\title{
Continuity of nursing care in Finnish primary health care settings: A 15-year follow-up
}

\author{
Risto Raivio*1,2, Eija Paavilainen ${ }^{3,4}$, Kari J. Mattila ${ }^{2,5}$ \\ ${ }^{1}$ Unit of Clinical Knowledge Support and Primary Health Care, Päijät-Häme Joint Authority for Health and Wellbeing, Lahti, \\ Finland \\ ${ }^{2}$ Department of General Practice, Faculty of Medicine and Life Sciences, University of Tampere, Tampere, Finland \\ ${ }^{3}$ School of Health Sciences (Nursing), Faculty of Social Sciences, University of Tampere, Tampere, Finland \\ ${ }^{4}$ Etelä-Pohjanmaa Hospital District, Seinäjoki, Finland \\ ${ }^{5}$ Center for General Practice, Pirkanmaa Hospital District, Tampere, Finland
}

Received: May 11, 2018

DOI: $10.5430 / \mathrm{cns} . v 7 \mathrm{n} 1 \mathrm{p} 11$
Accepted: August 15, 2018

Online Published: August 27, 2018

\begin{abstract}
Objective: Continuity is an essential part of high-quality nursing care. This study is the first systematic follow-up of Finnish primary health care patients assessing continuity of health centre nursing staff. The aim was to ascertain how longitudinal interpersonal continuity of care is related to patients' characteristics, their consultation experiences, and how continuity had changed over the 15-year study period.

Methods: A questionnaire survey was conducted among patients attending the health centres in the Tampere University Hospital catchment area from 1998 to 2013 . A total of 157,549 patients responded out of 363,464 in almost 60 health centres. We analysed the opinions of patients $(n=47,470)$ who had visited a nurse during the survey weeks. Opinions on the continuity of care were assessed with the question: "When visiting the health centre, do you usually see the same nurse", the alternatives being "yes" or "no". A binary logistic regression model was used.
\end{abstract}

Results: Almost two thirds of the respondents had met the same nurse when visiting their health care centre. Longitudinal interpersonal continuity of care decreased by 15 percentage $(67 \%-52 \%)$ during the study years. Continuity was connected to patient-related items such as a visit in the preceding 12 months (OR 1.32, 95\% CI 1.17-1.49) and non-urgency of the visit (OR $1.44,95 \%$ CI 1.27-1.63). The most prominent factor contributing to the sense of continuity of care was how attentively nurses had listened to their patients' problems and shown an interest in them and a willingness to answer their questions (OR 1.31, 95\% CI 1.120-1.43).

Conclusions: In the past 15 years patient-reported longitudinal interpersonal continuity of nursing care has declined. However continuity of care proved to enhance the experienced quality of primary health care. Continuity was best realized in nursing care when nurses had listened to their patients' problems, showed interest toward them and a willingness to answer their questions.

Key Words: Continuity of care, Patient-related questionnaire follow-up study, Primary health care, Quality of nursing care

\footnotetext{
*Correspondence: Risto Raivio; Email: risto.raivio@phhyky.fi; Address: Unit of Clinical Knowledge Support and Primary Health Care, Päijät-Häme Joint Authority for Health and Wellbeing, Keskussairaalankatu 7, 15850 Lahti, Finland.

Published by Sciedu Press 


\section{INTRODUCTION}

\subsection{The concept and meaning of continuity in nursing care}

Continuity is a basic principle and an essential component in high-quality nursing care. Continuity of care has a positive effect on the quality, efficiency and costs of basic health care - and on the health of the general public. ${ }^{[1-3]}$

Defining the concept of continuity of care requires reliable assessment and measurement. ${ }^{[4]}$ These aspects could be stud- ied by assessing consultations, communication, information, relationship and health care management. There are multiple instruments to measure different parts of continuity of primary care. Continuity of primary health care can be assessed in a patient perspective or organization and practice point of view. Definition of continuity of care has been discussed in literature as well as the influence of continuity of care. ${ }^{[3-8]}$

Different types of continuity of care and the explanation of terms emerged from literature ${ }^{[4,5]}$ is collected to the Table 1 .

Table 1. Definitions of different types of continuity ${ }^{[4,5]}$

\begin{tabular}{ll}
\hline $\begin{array}{l}\text { Different types (terms) of Continuity } \\
\text { of Care (CoC) }\end{array}$ & The aspect and explanation of the term \\
\hline $\begin{array}{l}\text { Longitudinal interpersonal (or relational) } \\
\text { continuity }\end{array}$ & $\begin{array}{l}\text { An ongoing therapeutic relationship between a patient and one or more providers. Care from the } \\
\text { same healthcare professional or as few professionals as possible, consistent with other needs. } \\
\text { The patient's judgement of co-ordinated and smooth progression of care. Services those are } \\
\text { flexible and adjusted to the needs of the individual over time. }\end{array}$ \\
$\begin{array}{l}\text { Experienced and flexible continuity } \\
\text { care settings, providing consistent communication and co-ordination of care for their patients. }\end{array}$ \\
Team continuity & $\begin{array}{l}\text { Care that follows the patient across settings (e.g. from primary care to hospital or vice versa). } \\
\text { A consistent and coherent approach to the management of a health condition that is responsive } \\
\text { to a patient's changing needs. }\end{array}$ \\
Cross-boundary continuity & $\begin{array}{l}\text { Care that is given or received in person on one site. } \\
\text { The use of information on past events and personal circumstances to make current care } \\
\text { appropriate for each individual. }\end{array}$ \\
\hline Geographic continuity &
\end{tabular}

The definition and the concept of continuity of care are related to other primary health care terms such as coordination and integration of care, accessibility, case management and patient-centered care. ${ }^{[9,10]}$ Common themes within these terms are personal relationship between patient and care provider and communication and co-operation between providers. ${ }^{[10]}$

Continuity of care has a positive influence on the outcome of patient care, the commitment to care and patients' experience of security, confidence and satisfaction. It enhances health care professionals' communication skills, trust, empathy and shared understanding with their patients. ${ }^{[3-8]}$

The value of continuity is to decrease the information asymmetry and to avoid the imbalance between patients' and caregivers' knowledge of relevant factors and details of care. It also increases shared understanding and goal alignment between the patient and the care provider. Furthermore known and trusted health care professional could enhance communication about patient's problems and sharing of the common goals of care. ${ }^{[3-8]}$

Lack of continuity may increase total costs of health care services. Discontinuity of care is associated with more admissions for ambulatory care sensitive conditions. It may also lead to delayed diagnosis and treatment. For patient lack of continuity can reduce satisfaction of and commitment to care. $^{[3-8]}$

Organization of care designed to maintain continuity is important for a high-quality nursing care. It includes assigning patients longstanding and permanent nurses who are responsible for multidisciplinary care coordination. Improvement in communication between patient, family and health care team requires openness and dialogue among different professionals. ${ }^{[1]}$

Other important elements for developing coordinating role of nurses in improving the continuity of care include nurses' competence, collaboration skills, commitment and resources. ${ }^{[12]}$

Continuity can be seen in informational, management and relational perspectives. ${ }^{[4-6]}$ According to Gulliford and coworkers ${ }^{[13]}$ evaluation of continuity of services calls for consideration of both patients' and professionals' perspectives. For patients, a continuous caring relationship is important, together with an identified health care professional. This requires combining patients' experiences of good quality care into important aspects of services such as case-management and multidisciplinary team-working. ${ }^{[13]}$ 
From the perspective of professionals, again, practices have been developed which integrate services as seamless and flexible multiprofessional working models. Organizing care in such a way as to enhance coordination and continuity is believed to be critical and crucial from both the nursing and the medical profession point of view. ${ }^{[14]}$

Knowledge of the patient's condition, local services, flexibility, coordinating role, and a holistic and collaborative approach to practice are key elements in nurses' promotion of continuity of care. ${ }^{[15]}$ In a review by Saultz and Lochner ${ }^{[16]}$ from the viewpoint of family medicine, a significant association was found between interpersonal continuity and improved preventive care and reduced hospitalization. The authors' definition of continuity was focused on continuity as a core principle of care, seen as the relationship between the professional and the patient. ${ }^{[16]}$

Concerning chronic disease management and continuity of care, continuity in the patient-provider relationship seems to be most important to patients with comorbid chronic conditions who need or make more visits and cannot easily be engaged in their own treatment plan. ${ }^{[14]}$

With an eye to improving patient outcomes and using community resources more effectively, the Chronic Care Model (CCM) was developed. ${ }^{[17]}$ It was designed to promote an evidence-based change in the routine delivery of care by promoting patient-centeredness and multiprofessional working practices, which are also key elements in enhancing continuity of primary health nursing care.

The CCM was planned especially for patients with chronic illnesses in primary health care settings. It aims to provide proactive, planned and patient-centered care seeking to improve patients' self-care and health. It is based on team work, and nurses and doctors working in pairs, seeking to ensure continuity of staff. ${ }^{[17]}$

\subsection{The Finnish health care system}

In the Finnish health care system mainly publicly funded municipal health care centres form the basis of services. ${ }^{[18]}$ Staff in these centres work mostly in teams or pairs and nurses and doctors form the core of the services. ${ }^{[19]}$ Nurses who assess the need and urgency of care are almost invariably patients' first contacts, either by telephone or face-to-face. Delegation of tasks from doctors to nurses is common. ${ }^{[19]}$ Although Finnish health care centres vary considerably in actual size and target population, ${ }^{[18,19]}$ the focus has been on systematically developing the quality of care, increasing its resources and integration, and emphasizing patients' role in their own care. ${ }^{[19,20]}$

\subsection{The aim of the study}

Prior to this present paper, there have been no systematic studies assessing longitudinal interpersonal continuity of care by primary health care nurses in Finland. International evidence is also lacking. We are aware of the complexity of defining and measuring the continuity of primary nursing care; as well as improving it in practice.

The aim here was to ascertain how longitudinal interpersonal continuity of care is related to certain features of patients and their experiences of consultation with nurses working in primary health care. How the patient-reported longitudinal interpersonal continuity of health centre nurse had changed over the study period was also studied.

\section{Methods}

\subsection{Setting}

The Department of General Practice at the University of Tampere sent a questionnaire to 65 primary health care centres in 1998, 1999, 2000, 2001, 2003, 2005, 2007, 2009, 2011 and 2013. The questionnaire was given every study year to patients attending for treatment during one particular week. The questions were based on international studies ${ }^{[19]}$ and adapted to the special characteristics of Finnish primary health care. ${ }^{[20]}$

The questionnaire was piloted in the Pirkanmaa area in 1998 , at which time 9,276 patients responded. In 1999, the study was extended to primary health care centres located in the catchment area of Tampere University Hospital. At the request of primary health care centres, from the year 2001 the questionnaire was distributed every second year. There were 65 health centres in this area, serving a total population of 1.2 million.

\subsection{Data collection}

Data were collected during the same calendar week 39 , in September. Week 39 was chosen for data collection as the Finnish calendar week 39 is an ordinary autumn week without any bank holiday. Reception staff distributed the questionnaire to patients visiting physicians or nurses due to illness from Monday to Friday between 8 a.m. and 4 p.m. Patients placed the anonymously filled questionnaires in a box in the waiting room after their consultation. During the data collection periods, 363,464 patients visited the practices, and 157,549 responded. The response rate varied yearly from $39 \%$ to $53 \%$. In this study, the replies of those patients who visited a nurse during the study week in $1998-2013$ were analysed. The total number of patients was 47,490 (see Table 2). 
Table 2. Total number of responding patients visiting a doctor or a nurse in health centres during the respective study weeks in 1998-2013 and proportion of contacts with a nurse

\begin{tabular}{lllll}
\hline \multirow{2}{*}{ Year } & \multicolumn{3}{c}{ Respondents' contact } & $\begin{array}{l}\text { Proportion of contacts with a } \\
\text { nurse (\%) }\end{array}$ \\
\cline { 2 - 5 } & Doctor $(\mathbf{n})$ & Nurse $(\mathbf{n})$ & All $(\mathbf{n})$ & 27.0 \\
1998 & 6,377 & 2,356 & 8,733 & 30.9 \\
1999 & 17,132 & 7,660 & 24,792 & 34.8 \\
2000 & 14,887 & 7,952 & 22,839 & 33.5 \\
2001 & 10,724 & 5,402 & 16,126 & \\
2002 & & & & 32.7 \\
2003 & 9,783 & 4,754 & 14,537 & \\
2004 & & & & 31.1 \\
2005 & 10,540 & 4,765 & 15,305 & \\
2006 & & & & 31.8 \\
2007 & 10,557 & 4,919 & 15,476 & 36.1 \\
2008 & & & & \\
2009 & 5,956 & 3,372 & 9,328 & 34.6 \\
2010 & & & & \\
2011 & 5,791 & 3,063 & 8,854 & 36.2 \\
2012 & & & & 32.8 \\
2013 & 5,721 & 3,247 & 144,958 & \\
Total & 97,468 & 47,490 & &
\end{tabular}

\subsection{Questionnaire}

Patients were asked background information: gender, age, reason for visit (acute event, other urgent or non-urgent matter), visits to a nurse in the health centre prior to this present, which health care provider the patient had met, evaluation of the consultation and opinion of the visit (see Tables 3-5).

From 2005 on the question "Do you have a particular doctor appointed for you at the health centre?" was added to the questionnaire. The number of respondents to this question was 18,093 (see Table 3). A particularly doctor appointed for a patient signifies here that patients were assigned to a specific doctor by health organizations based on where they lived without their actually having the freedom to choose the doctor they were going to see.

Further, from 2009 onward the question: "In the last 12 months, how many times have you visited the health centre prior to this visit?" was added. The number of respondents to this question was 9,682 (see Table 3).

Opinions on the longitudinal personal continuity of care were assessed with the question: "When visiting the health centre, do you usually see the same nurse?", the alternatives being "yes" or "no". Respondents graded the quality of service on a scale traditional in the Finnish school system and familiar to all patients, grades ranging from 4 ("very poor") to 10 ("excellent"). The highest score 10 was considered the "top-box" and represented the best possible quality. The frequency of this top score was determined for each domain compared to other scores (4 to 9).

The number of respondents varied in study years and between questions (see Table 3). The respondents answered the quality questions if they needed and met the service in question.

\subsection{Statistical analysis}

IBM SPSS version 20.0 for statistical analysis was used. The statistical significance of differences in frequencies between the groups was tested by $\chi^{2}$ test. We used a binary logistic regression model on features of patients, and on patients' evaluation of consultation with nurses. To study how the various factors were connected with the continuity of care (dependent variable) we used both univariate and multivariate regression models. Patient-related factors and quality factors were dichotomized and are presented in Tables 4 and 5.

\subsection{Ethics}

This study observed the ethical principles prevailing under Finnish law. The research was non-invasive and not aimed at any individual person. The research data were based on information provided by respondents giving their opinions anonymously and voluntarily for research purposes. Nei- 
ther the personal nor the medical history of the respondents was used in the research, nor will the survey results be combined with any other data. The responses cannot be used to identify individual respondents. Health centres participated voluntarily in the research.

The concurrent joint Ethics Committee of the University of Tampere and Tampere University Central Hospital in their meeting on August 6, 2013 ruled that according to Finnish legislation no ethical assessment or approval was mandatory for this study.

\section{Results}

\subsection{Patients' characteristics}

The total number of replies from those patients who visited the health centres due to illness during the study week in all study years is shown in Table 2. The proportion of patients visiting a nurse in health centres increased slightly from 1998 to 2013 .
Of patients who had met a nurse, $61 \%$ were women, $52 \%$ were younger than 60 years, $40 \%$ needed acute or sub-acute treatment, and $55 \%$ had made at least one prior visit to a nurse in the health centre during the preceeding 12 months and $59 \%$ met the same nurse (see Table 3 ). Half of the respondents $(51 \%)$ reported having a doctor particularly appointed to them at the health centre.

In the case of patients who usually met the same nurse at the health centre, continuity of care seem to be realized in the same way in both genders (see Table 3). Nor were there any differences in ratings between the age groups. In nonurgent visits and in visits to a nurse over the 12 months prior to the actual visit, continuity of nursing care was felt to be actualized slightly more often. Up to $60 \%$ of those patients, who reported having a particular doctor appointed for them, could usually meet the same nurse. Correspondingly, only $46 \%$ usually met the same nurse if they had no appointed doctor (see Table 4).

Table 3. Number and proportion (\%) of missing data and respondents by patients' gender, age, urgency of consultation, prior visit, particular allocated doctor and ability to meet usually the same nurse

\begin{tabular}{|c|c|c|c|c|}
\hline & \multicolumn{2}{|c|}{ Missing data } & \multicolumn{2}{|c|}{ Respondents } \\
\hline & $\mathbf{n}$ & $\%$ & $\mathbf{n}$ & $\%$ \\
\hline Gender & 392 & 0.8 & 47,098 & 100 \\
\hline Female & & & 28,927 & 61.4 \\
\hline Male & & & 18,171 & 38.6 \\
\hline Age & 6,552 & 13.8 & 40,938 & 100 \\
\hline$<60$ years & & & 21,370 & 52.2 \\
\hline$\geq 60$ years & & & 19,568 & 47.8 \\
\hline Urgency & 7,421 & 15.6 & 40,069 & 100 \\
\hline Acute/less acute & & & 15,874 & 39.6 \\
\hline Non-urgent & & & 24,195 & 60.4 \\
\hline Meets usually the same nurse & 5,907 & 12.4 & 41,583 & 100 \\
\hline Yes & & & 24,659 & 59.3 \\
\hline No & & & 16,924 & 40.7 \\
\hline Visit in previous 12 months ${ }^{*}$ & - & & 9,682 & 100 \\
\hline Yes & & & 5,363 & 55.4 \\
\hline No & & & 4,319 & 44.6 \\
\hline Specific doctor ${ }^{* *}$ & 1,273 & 6.6 & 18,093 & 100 \\
\hline Appointed & & & 9,298 & 51.4 \\
\hline Not appointed & & & 8,795 & 48.6 \\
\hline
\end{tabular}

Note. ${ }^{*}$ Question added to survey in 2009; ${ }^{* *}$ Question added to survey in 2005

Overall, two thirds of the patients gave the highest marks (10 points) for quality aspects when they had the possibility to meet the same nurse at the health centre (see Table 5). The difference in giving the best possible grades on consultation between those who could meet the same nurse at the health

centre and those who could not varied from 7 to 9 percentage points and was statistically significant $(p<.001)$ in all quality aspects (see Table 5).

In univariate regression analysis all patient-related items and all patients' experiences of consultation with a nurse 
explained continuity (see Table 6). Confidentiality and the sense of receiving help, and the willingness of the nurse to give answers contributed to the correlation. Also experience of the behaviour of the nurse during the consultation, the information given regarding medication and tests, and the adequacy of instructions on further care were related to the continuity of care.

Table 4. Number and proportion (\%) of patients and respondents who were usually able to meet the same nurse by gender, age, urgency of consultation, prior visit particular allocated doctor

\begin{tabular}{|c|c|c|c|c|c|}
\hline \multirow{2}{*}{ Patient characteristics } & \multicolumn{3}{|c|}{ Do you usually meet the same nurse? } & \multirow{2}{*}{ Chi square } & \multirow{2}{*}{$p$-value } \\
\hline & Respondents (n) & Yes $(\%)$ & No $(\%)$ & & \\
\hline Gender & & & & 10.486 & .001 \\
\hline Female $(\mathrm{n}=28,927)$ & 25,362 & 59.9 & 40.1 & & \\
\hline Male $(n=18,171)$ & 15,943 & 62.9 & 41.8 & & \\
\hline Age & & & & 5.051 & .025 \\
\hline$<60$ years $(\mathrm{n}=21,370)$ & 19,094 & 59.2 & 40.8 & & \\
\hline$\geq 60$ years $(n=19,568)$ & 16,961 & 60.4 & 39.6 & & \\
\hline Urgency & & & & 34.636 & $<.001$ \\
\hline Acute/less acute $(\mathrm{n}=17,134)$ & 13,844 & 57.2 & 42.8 & & \\
\hline Non-urgent $(n=25,968)$ & 21,563 & 60.4 & 39.6 & & \\
\hline Visit in previous 12 months* & & & & 56.93 & $<.001$ \\
\hline Yes $(n=5,363)$ & 4,894 & 57.5 & 42.5 & & \\
\hline No $(n=4,319)$ & 3,391 & 49.1 & 50.9 & & \\
\hline Specific doctor ${ }^{* *}$ & & & & 331.729 & $<.001$ \\
\hline Appointed $(\mathrm{n}=9,298)$ & 7,719 & 60.4 & 39.6 & & \\
\hline Not appointed $(\mathrm{n}=8,795)$ & 7,843 & 45.9 & 54.1 & & \\
\hline
\end{tabular}

Note. ${ }^{*}$ Question added to survey in $2009 ;{ }^{* *}$ Question added to survey in 2005

Table 5. Number and proportion (\%) of patients who gave the highest ratings (10 points) for quality aspects of consultation compared to the reply to the question "When you visit the health centre, do you usually meet the same nurse?"

\begin{tabular}{|c|c|c|c|c|c|c|}
\hline \multirow{3}{*}{ Patient characteristics } & \multicolumn{4}{|c|}{ Do you usually meet the same nurse? } & \multirow{3}{*}{$\begin{array}{l}\text { Chi } \\
\text { square }\end{array}$} & \multirow{3}{*}{$p$-value } \\
\hline & \multicolumn{2}{|c|}{ Yes } & \multicolumn{2}{|c|}{ No } & & \\
\hline & $\mathbf{n}$ & $\%$ & n & $\%$ & & \\
\hline $\begin{array}{l}\text { Did you get information about the treatment options for } \\
\text { your particular health problem? }\end{array}$ & & & & & 179.777 & $<.001$ \\
\hline Highest score $(\mathrm{n}=13,192)$ & 7,744 & 65.3 & 4,108 & 34.7 & & \\
\hline Other $(\mathrm{n}=15,469)$ & 7,970 & 57.2 & 5,972 & 42.8 & & \\
\hline $\begin{array}{l}\text { Did you get clear and adequate instructions for further care } \\
\text { and treatment? }\end{array}$ & & & & & 165.449 & $<.001$ \\
\hline Highest score $(\mathrm{n}=17,306)$ & 9,924 & 63.9 & 5,618 & 36.1 & & \\
\hline Other $(\mathrm{n}=15,390)$ & 7,843 & 56.5 & 6,037 & 43.5 & & \\
\hline $\begin{array}{l}\text { Did the nurse listen to your problems and did s/he show } \\
\text { interest toward you and willingness to answer your questions? }\end{array}$ & & & & & 320.616 & $<.001$ \\
\hline Highest score $(\mathrm{n}=22,110)$ & 12,832 & 64.2 & 7,140 & 35.8 & & \\
\hline Other $(\mathrm{n}=16,235)$ & 7,962 & 54.7 & 6,594 & 45.3 & & \\
\hline Did you feel that your matters were dealt with confidentially? & & & & & 218.527 & $<.001$ \\
\hline Highest score $(\mathrm{n}=25,868)$ & 14,645 & 62.6 & 8,743 & 37.4 & & \\
\hline Other $(n=14,264)$ & 6,959 & 54.6 & 5,778 & 45.4 & & \\
\hline Did you get help for your health problem? & & & & & 151.620 & $<.001$ \\
\hline Highest score $(\mathrm{n}=21,391)$ & 12,052 & 62.6 & 7,194 & 37.4 & & \\
\hline Other $(n=14,819)$ & 7,447 & 55.8 & 5,894 & 44.2 & & \\
\hline
\end{tabular}


Table 6. Patient-related and consultation-related covariates explaining continuity of care (same nurse) in univariate and multivariate regression model

\begin{tabular}{|c|c|c|c|c|}
\hline \multirow{2}{*}{ Variable groups } & \multicolumn{2}{|c|}{ Univariate analysis } & \multicolumn{2}{|c|}{ Multivariate analysis" } \\
\hline & OR $(95 \%$ CI $)$ & $p$-value & OR $(95 \%$ CI $)$ & $p$-value \\
\hline \multicolumn{5}{|l|}{ Patient-related items } \\
\hline Woman & $1.07(1.03-1.11)$ & .001 & $1.05(0.94-1.19)$ & .391 \\
\hline Age 60 years or more & $1.05(1.01-1.10)$ & .025 & $1.08(0.96-1.22)$ & .197 \\
\hline Non-urgent visit & $1.14(1.10-1.19)$ & $<.001$ & $1.44(1.27-1.63)$ & $<.001$ \\
\hline Visit in preceding 12 months & $1.40(1.28-1.53)$ & $<.001$ & $1.32(1.17-1.49)$ & $<.001$ \\
\hline Appointed doctor in Health Centre & $1.80(1.69-1.92)$ & $<.001$ & $2.13(1.89-2.40)$ & $<.001$ \\
\hline \multicolumn{5}{|l|}{ Consultation evaluation $^{* *}$} \\
\hline Received sufficient information & $1.41(1.34-1.49)$ & $<.001$ & $1.11(1.01-1.22)$ & .033 \\
\hline Received adequate instructions & $1.36(1.30-1.43)$ & $<.001$ & $0.98(0.89-1.09)$ & .719 \\
\hline Felt nurse listened and showed interest in their problems & $1.49(1.43-1.56)$ & $<.001$ & $1.31(1.20-1.43)$ & $<.001$ \\
\hline Felt confident about confidentiality & $1.39(1.33-1.45)$ & $<.001$ & $1.07(0.99-1.17)$ & .104 \\
\hline Got help for their health problem & $1.33(1.27-1.39)$ & $<.001$ & $1.05(0.97-1.14)$ & .225 \\
\hline
\end{tabular}

Note. ${ }^{*}$ In the model all variables of the group ${ }^{* *}$ For the precise formulation of the questions see Table 4

\subsection{Patient-related items in multivariate analysis}

In multivariate analysis appointed doctor (OR $2.13,95 \% \mathrm{CI}$ 1.89-2.40), reason (non-urgent) for visit (OR $1.44,95 \% \mathrm{CI}$ 1.27-1.63) and visit in the preceding 12 months (OR 1.32, 95\% CI 1.17-1.49) were most clearly, and also statistically significantly $(p<.001)$ linked to continuity of care (see Table $5)$.

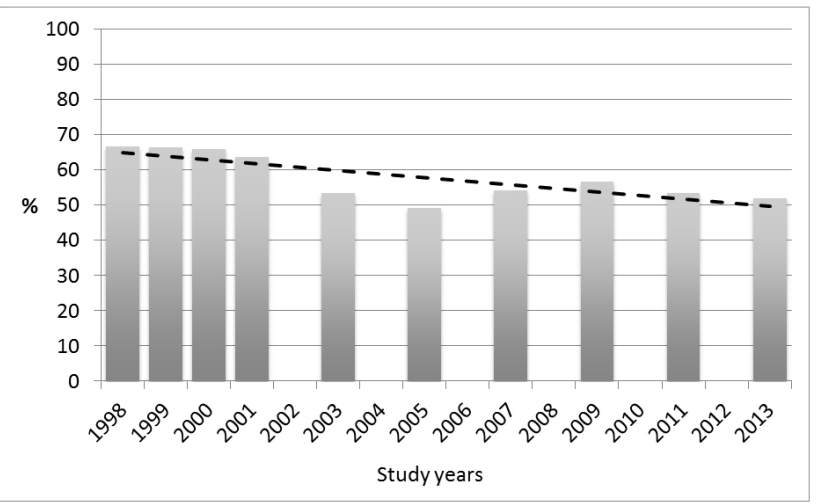

Figure 1. The percentage and trend line of those patients who usually saw the same nurse in the study years (1998-2013). Continuity of care was assessed by the question "When visiting the health centre, do you usually see the same nurse?

\subsection{Patients' experiences of consultation}

The way the nurse had listened to the patient and showed interest in the patient's problems was the only indicator statistical significantly $(p<.001)$ associated with the continuity of care in both the univariate (OR 1.49, 95\% CI 1.43-1.56) and the multivariate regression model (OR $1.31,95 \% \mathrm{CI}$ $1.20-1.43)$.

\subsection{The trend in continuity of nursing care}

Personal continuity of care decreased 15 per cent units (67\%52\%) from the study year 1998 to 2013 (see Figure 1). At most, over two thirds (67\%) of patients in 1998 reported that when they visited the health centre, they usually met the same nurse in that year, as against under half (49\%) in 2005.

\section{Discussion}

A number of features and aspects of patients and experiences of consultation proved to be associated with continuity of primary care nursing. The most clearly determining factor was that patients felt that the nurse had listened, shown an interest in their problems and were willingness to answer their questions. A doctor particularly appointed for the patient was also significantly linked to a better sense of continuity in nursing care.

The non-urgency of the visit and previous visits to a nurse in the health centre were factors significant in promoting continuity of nursing care. The variables connected with continuity in patients' experiences here were mostly similar to those noted in previous studies ${ }^{[21]}$ using similar methods. However, the combination of factors explaining the continuity of nursing care over the long period covered by this study clearly showed the most important aspect of high-quality care.

Patients in primary care appreciate continuity. ${ }^{[22,23]}$ Also according to previous studies, characteristics related to the 
patient, e.g. physical comfort, emotional support and respect for patient preferences increase satisfaction. ${ }^{[24]}$ In this study, patients' gender or age was not related to the sense of continuity of nursing care. However, patients with chronic diseases, particularly when they feel most vulnerable as at the initial diagnostic stage, seem to benefit from the continuity of care and a long treatment relationship with doctor and nurse. ${ }^{[25]}$

On the other hand, continuity alone is no guarantee of good and efficient health care. Features related to the health care system, e.g. integrated services of doctors and nurses, and team-work, improve patient care and health outcomes. ${ }^{[26]}$ Patients value ease of contacting a nurse, shorter waiting times, rapid response and a less formal relationship and communicative style. Good communication and listening, proper instructions and confidentiality during the consultation increase satisfaction and enhance the perception of continuity of care. ${ }^{[27]}$ These aspects also emerged in the present study. Listening to the patient and showing an interest in the patient's problems were most significantly related to the sense of continuity of care.

The CCM has been applied in Finland in improving especially primary health care. ${ }^{[28,29]}$ With the shortage of primary care doctors and with nurses acting as the main non-physician working health professionals along with the doctors, there has been a need to clarify the role of nurses in primary health care not only in Finland but also in other developed countries. There is also an increased demand for provision of team-based primary care. ${ }^{[19]}$

In our previous study the most prominent factor contributing to a sense of continuity of care is having a doctor specifically appointed to the patient. ${ }^{[20]}$ In light of this finding and also previous literature on continuity of care, it is relevant to explore the contribution of consultation with the same nurse. Patients' experiences are essential in arranging services based on their needs and integrating them as well as possible for multiprofessional, cost-effective practices.

It appears that during the study years (1998-2013) the continuity of Finnish primary nursing care decreased and leaves much to be desired. According to the present results, patients were less satisfied with the continuity of care at the end of the study in 2013 than they were at the outset. The number of patients who would most benefit from the possibility of seeing the same physician and nurse has increased. It is disconcerting that at the same time the continuity of care has not improved.

Especially those patients who are fragile, particularly elderly patients with long-term conditions and multimorbidity and patients who need or use the facilities most for example drug and alcohol misusers, the mentally ill, young people and families with social problems, benefit from the continuity of care ${ }^{[20]}$ Such patients could profit from a care manager, who, together with a team of professionals, would integrate and coordinate their care, and also empower them to promote their own care. For these patients the possibility of choosing their own doctor and nurse would be ideal. A particular nurse and doctor pair assigned to them would at least ensure the continuity of their care.

\section{Strengths and limitations}

This study constitutes the first longitudinal, systematic inquiry into interpersonal continuity of primary health care nursing in Finland. The same questionnaire and methodology in reporting continuity in the case of primary health care doctors in Finland has previously been used. ${ }^{[21]}$ The challenges involved in studies using a questionnaire survey are obvious. ${ }^{[20-24]}$ Reliance on reception staff distributing questionnaires is flawed as a means of systematic inquiry and involves a notable sampling bias. Since, however, the same flaws apply all data obtained, it is reasonable to conclude that comparison over time is still robust. ${ }^{[20,22]}$ The low overall response rate $(45 \%)$ is a limitation. In some of the questions the limited sample size could also affect the possibility of drawing conclusions. The single question addressing longitudinal interpersonal continuity of care by asking "When visiting the health centre, do you usually see the same nurse?" and graded the perceived quality of service on a scale ranging from 4-10 could be judged superficial information of actual nursing care. These notwithstanding, the overall data and the process of assessing patients' views can be generalized and considered comprehensive. ${ }^{[20,22]}$ The adoption of the top-box score was inspired by its use in other patient satisfaction measurements. ${ }^{[30]}$

During the fifteen-year study period it was possible to gather an extensive sample of patient experiences of personal continuity of care by health centre nurses. In this study area, with 1.2 million inhabitants, there are both small rural health centres and large health centres in the conurbations. ${ }^{[20,22]}$ The population of the study area has not significantly changed. In contrast the number of respondents varied to some extent during the study years. One reason for this might be organizational and structural changes within and between the municipalities arranging primary health care services. ${ }^{[19]}$

While there were fewer respondents, the number of patients visiting health centres also declined. The simplest patient cases have gradually moved from health centres to the growing network of occupational health services, while patients with long-term conditions and multimorbidity seem to remain the responsibility of health centres. ${ }^{[19]}$ These patients 
also tend to need more services and longer appointments.

Some attempts were also made to identify the reason for non-response. Reasons noted were, for example, forgetting glasses at home, being in a hurry or not wishing, for some reason or other, to answer the questionnaire. ${ }^{[22]}$

The patients who chose to respond were those who had an opinion and wanted to express it. The findings cover a long period of patients' experiences of primary care in one country. The respondents' views cannot be taken as representative of the whole population, but are likely to be representative of the main population using primary health care nursing services. They may also be considered relevant internationally, in developing primary health care models aiming to advance patient centred care and continuity.

\section{Conclusions}

This study underlines the importance of the patient's perspective in assessing nursing care. Longitudinal interpersonal continuity of nursing care in health centres proved to enhance the experienced quality of care. Continuity was best achieved when nurses had listened to patients' problems and shown an interest in them and a willingness to answer their questions. Continuity of nursing care was also enhanced when patients had a doctor particularly appointed to them.

Organization of primary health care services in such a way that at least those patients who need care most could have a particularly appointed nurse and doctor for them may also guarantee them the continuity of nursing care.

\section{ACKNOWLedgements}

Acknowledgements to Central Finland and Pohjanmaa area health centres; the Department of General Practice in the Medical School of the University of Tampere and the Centre for General Practice of the Pirkanmaa Hospital District for co-ordinating, designing and collecting the data.

\section{FUNDING}

This study was financially supported by the Competitive State Research Financing of the Expert Responsibility area of Tampere University Hospital.

\section{CONFLiCTS OF InTEREST Disclosure}

The authors declare they have no conflicts of interest.

\section{REFERENCES}

[1] McWhinney IR. Primary care: Core values. Core values in a changing world. BMJ. 1998; 316(7147): 1807-1809. https://doi.org/ $10.1136 / \mathrm{bmj} .316 .7147 .1807$

[2] Starfield B. Primary care: An increasingly important contributor to effectiveness, equity, and efficiency of health services. SESPAS report. Gaceta Sanitaria/S.E.S.P.A.S. 2012; 26(Suppl 1): 20-26.

[3] Kringos D, Boerma W, Bourgueil Y, et al. The strength of primary care in Europe: An international comparative study. BJGP. 2013; 63(616): e742-50. PMid: 24267857. https://doi.org/10.339 9/bjgp13X674422

[4] Haggerty J, Reid R, Freeman G, et al. Continuity of care: a multidisciplinary review. BMJ. 2003; 327: 1219-1221. PMid: 14630762. https://doi.org/10.1136/bmj.327.7425.1219

[5] Alazri M, Heywood P, Neal RD. Continuity of care: literature review and implications. Sultan Qaboos Univ Med J. 2007; 7: 197-206. PMid: 21748104.

[6] Greenhalgh T, Heath I. Measuring quality in the therapeutic relationship. The King's Fund inquiry into the quality of general practice in England: discussion paper 2. London: The Kings' Fund; 2010.

[7] Freeman G, Hughes J. Continuity of care and the patient experience. Research paper: An Inquiry into the Quality of General Practice in England. London, England: The King's Fund; 2010.

[8] Salisbury C, Wallace M, Montgomery AA. Patients' experience and satisfaction in primary care: Secondary analysis using multilevel modelling. BMJ. 2010; 341: c5004. PMid: 20940212. https: //doi.org/10.1136/bmj.c5004

[9] Haggerty JL, Pineault R, Beaulieu MD, et al. Practice features associated with patient-reported accessibility, continuity, and coordination of primary health care. Ann Fam Med. 2008 Mar-Apr; 6(2): 116-23. PMid: 18332403. https://doi.org/10.1370/afm. 802

[10] Uijen AA, Schers HJ, Schellevis FG, et al. How unique is continuity of care? A review of continuity and related concepts. Fam Pract. 2012 Jun; 29(3): 264-71. PMid: 22045931. https ://doi.org/10 $.1093 /$ fampra/cmr 104

[11] Gutierrez K. Critical care nurses' perceptions of and responses to moral distress. Dimens Crit Care Nurs. 2005; 24(5): 229-241. PMid: 16258357. https://doi.org/10.1097/00003465-200509000 $-00011$

[12] Mezey M, Kobayashi M, Grossman S, et al. Nurses improving care to health system elders (NICHE). Implementation of best practice models. JONA. 2004; 34(10): 451-457. https://doi .org/10.1 097/00005110-200410000-00005

[13] Gulliford M, Naithani S, Morgan M. What is "continuity of care"? J Health Serv Res Policy. 2006; 11(4): 248-250. PMid: 17018200. https://doi.org/10.1258/135581906778476490

[14] Servellen G, Fongwa M, D'Errico E. Continuity of care and quality care outcomes for people experiencing chronic conditions: A literature review. Nurs Health Sci. 2006; 8: 185-195. PMid: 16911180. https://doi.org/10.1111/j.1442-2018.2006.00278.x

[15] Aspinal F, Gridley K, Bernard S, et al. Promoting continuity of care for people with long-term neurological conditions: The role of the neurology nurse specialist. Adv Nurs. 2012 Oct; 68(10): 230919. PMid: 22276700 . https://doi.org/10.1111/j.1365-264 8.2011.05928. $\mathrm{x}$

[16] Saultz J, Lochner J. Interpersonal continuity of care and care outcomes: A critical review. Ann Fam Med. 2005 Mar-Apr; 3(2): 159-66. PMid: 15798043. https://doi.org/10.1370/afm.285

Published by Sciedu Press 
[17] Coleman K, Austin B, Brach C, et al. Evidence on the Chronic Care Model in the new millenium. Health Aff (Millwood). 2009 Jan-Feb; 28(1): 75-85. PMid: 19124857. https://doi.org/10.1377/hl thaff.28.1.75

[18] Teperi J, Porter ME, Vuorenkoski L, et al. The Finnish Health Care System: A Value-Based Perspective. Sitra Reports 82, Helsinki 2009 [accessed 27.3.2015]. Available from: http://www.sitra.fi/j ulkaisut/raportti82.pdf?download=Download+pdf

[19] Kokko S. Integrated primary health care: Finnish solutions and experiences. Int J Integr Care. 2009 Jun 25; 9: e86. PMid: 19590612. https://doi.org/10.5334/ijic.310

[20] Raivio R, Holmberg-Marttila D, Mattila K. Patients' assessments of the continuity of primary care in Finland: a 15-year follow-up questionnaire survey. British Journal of General Practice. 2014; e657e663. PMid: 25267052. https://doi .org/10.3399/bjgp14X6 81841

[21] Grol R, Wensing M, Mainz J, et al. Patients' priorities with respect to general practice care: an international comparison. European Task Force on Patient Evaluations of General Practice (EUROPEP). Fam Pract. 1999; 16(1): 4-11. PMid: 10321388. https: //doi.org/10.1093/fampra/16.1.4

[22] Raivio R, Jääskeläinen J, Holmberg-Marttila D, et al. Assessment of patient satisfaction in primary health care - reliable information and benchmarking. Finnish Medical Journal. 2008; 63(33): 2623-2626.

[23] Aboulghate A, Abel G, Elliott MN, et al. Do English patients want continuity of care, and do they receive it? Br J Gen Pract. 2012; 62(601): 567-575. PMid: 22867681. https ://doi.org/10.339 9/bjgp12X653624
[24] Allan J, Schattner P, Stocks N, et al. Does patient satisfaction of general practice change over decade? BMC Fam Pract. 2009; 10: 13. PMid: 19200400. https://doi.org/10.1186/1471-2 296-10-13

[25] Von Butzingslöwen I, Eliasson G, Sarvimäki A, et al. Patients' views on interpersonal continuity in primary care: A sense of security based on four core foundations. Fam Pract. 2006; 23: 210-219. PMid: 16361395. https://doi.org/10.1093/fampra/cmi103

[26] Wilson PM, Brooks F, Procter S, et al. The nursing contribution to chronic disease management: A case of public expectation? Qualitative findings from a multiple case study design in England and Wales. Int J Nurs Stud. 2012 Jan; 49(1): 2-14. PMid: 22093577. https://doi.org/10.1016/j.ijnurstu.2011.10.023

[27] Jenkinson C, Coulter A, Bruster S, et al. Patients' experiences and satisfaction with health care: Results of a questionnaire study of specific aspects of care. Qual Saf Health Care. 2002; 11: 335-339. PMid: 12468693. https://doi.org/10.1136/qhc.11.4.335

[28] Heinänen T, Mäntyranta T, Maijanen S, et al. Läpimurtomallilla terveyshyötyä tuottamaan. Finnish Medical Journal. 2011; 22: 1841-45.

[29] Komulainen J, Mäkinen R, Rintala R, et al. Kansallisesta terveys- ja hoitosuunnitelmasta tuli yhtenäinen. Finnish Medical Journal. 2012; 3: $173-6$.

[30] Tom JO, Mangione-Smith R, Solomon C, et al. Integrated personal health record use: association with parent-reported care experiences. Pediatrics. 2012; 130(1): 183-90. PMid: 22689872. https://doi.org/10.1542/peds.2011-1786 